\title{
Microtubule Polarity in the Peripheral Processes of Trigeminal Ganglion Cells: Relevance for the Retrograde Transport of Herpes Simplex Virus
}

\author{
Kimberly S. Topp, Lauren B. Meade, and Jennifer H. LaVail \\ Neuroscience Program and Department of Anatomy, University of California San Francisco, San Francisco, California \\ 94143
}

The directional movement of many cellular organelles in neurons is dependent on polarized microtubules and directionspecific motor molecules. Microtubules are also thought to mediate the retrograde transport of herpes simplex virus (HSV) in sensory neurons. To define the cellular machinery responsible for retrograde axonal transport of $\mathrm{HSV}$, we have investigated the polarity of microtubules in the peripheral axons of trigeminal ganglion neurons. The long ciliary nerves of rabbits were prepared for a standard "hook assay" of microtubule polarity. Axons in cross-sectioned nerves contained microtubules with almost uniform orientation. The fastgrowing, plus ends of these axonal microtubules are located distal to the cell body and the slow-growing, minus ends are directed centrally.

To determine the role played by microtubules in the retrograde transport of HSV in these axons, we injected the retrobulbar space of mice with the microtubule-inhibiting drugs colchicine, vinblastine, or nocodazole or with the microfilament inhibitor cytochalasin $D$ and $1 \mathrm{~d}$ later inoculated the cornea with HSV. We found that colchicine, vinblastine, or nocodazole reduced by $52-87 \%$ the amount of virus recovered from the ganglion $3 \mathrm{~d}$ postinoculation, compared to vehicle-treated animals. In contrast, cytochalasin D or $\beta$-lumicolchicine did not significantly reduce the amount of HSV recovered from the ganglion. We conclude that the retrograde axonal transport of HSV from axon endings in the cornea to the trigeminal ganglion cell bodies requires intact microtubules and occurs in a plus-to-minus direction on the microtubules. Our data are consistent with the hypothesis that the retrograde axonal transport of $\mathrm{HSV}$ is mediated by a minus end-directed motor molecule, for example, cytoplasmic dynein.

[Key words: axonal transport, colchicine, vinblastine, nocodazole, cytochalasin, dynein]

Recurrent herpes simplex (HSV) infections of the eye are a major clinical problem. Episodes of ocular herpes may lead to corneal scarring, uveitic glaucoma, uveitic cataract, or retinitis.

\footnotetext{
Received Apr. 8, 1993; revised June 30, 1993; accepted July 6, 1993.

We are grateful to Dr. Lenore Pereira for her gift of herpes virus and to $\mathrm{Mr}$. Pedro Paz and Ms. Ann Nomoto for technical support. This work was supported by NIH Grants EY08773 (J.H.L.) and EY06322 (K.S.T.). L.B.M. was supported by a UCSF Student Research Committee Fellowship.

Correspondence should be addressed to Dr. Kimberly S. Topp, Department of Anatomy, Box 0452, University of California San Francisco, San Francisco, California 94143-0452.

Copyright (C) 1994 Society for Neuroscience $0270-6474 / 94 / 140318-08 \$ 05.00 / 0$
}

After disruption of the corneal epithelium, HSV can invade neuronal processes in the epithelium and stroma. The glycoprotein-rich envelope of the virion is thought to fuse with the host cell membrane prior to entry of the virus into the cell (see Roizman and Sears, 1991, for review). The viral capsid and some of the associated tegument proteins are then transported in a retrograde dircetion by trigeminal nerve axons to their cell bodies in the ophthalmic division of the trigeminal ganglion. Here the HSV may enter a latent state or replicate and be packaged in a membrane-bound vesicle destined for transport in an anterograde direction to both the CNS and the peripheral tissues (LaVail et al., 1991). The bidirectional axonal transport of HSV requires a cytoskeletal framework, energy, and translocator molecules. In addition, directional cues on the capsid and tegument as well as on the vesicle that contains mature HSV must be specific for retrograde and anterograde transport, respectively.

Microtubules are thought to play a central role in the transport of recycled proteins, vesicles in the endocytic and lysosomal systems, and mitochondria from the axon terminal to the soma (LaVail and LaVail, 1974; Bisby, 1982). Previous studies indicate that HSV takes advantage of the host neuron's natural machinery for retrograde axonal transport, using microtubules for translocation from the nerve terminals in the periphery to the cell bodies of dorsal root ganglion neurons in vivo (Kristensson et al., 1971). Microtubules and translocator molecules have also been implicated in the transport of HSV from the neurites to the cell bodies of dorsal root ganglion cells in vitro (Kristensson et al., 1986). However, no study has yet provided quantitative evidence of the dependence of HSV transport on intact microtubules in metabolically active neurons.

Microtubule polarity is established during development of the neuron and dictates the direction of organelle transport, in conjunction with translocator molecules. The polarity is defined by the kinetics of assembly and disassembly of the tubulin polymer; monomeric tubulin is added and removed at a faster rate at the plus end and at a much slower rate at the minus end of microtubules. The microtubules within neurites that extend from multipolar neurons in culture are oriented with their plus ends directed toward the growth cones (Baas et al., 1989; Baas and Ahmad, 1993). During development the axon maintains this microtubule orientation. However, microtubules of opposite polarity are added to dendritic processes. In contrast, unipolar sensory neurons develop from bipolar neuroblasts in which migration of the cell body toward the periphery of the ganglion leads to the formation of a single neurite that is divided into peripheral and central processes (Ramon y Cajal, 1952; Stainier and Gilbert, 1991). 
The peripheral processes that supply the corneal epithelium are thin, unmyelinated fibers that end as free nerve endings. In addition to their sensory, afferent responses to chemical, mechanical, or thermal stimuli (Rozma and Beuerman, 1982), these unipolar neurons also serve an efferent role by releasing neuropeptides that mediate local inflammatory responses (Holzer, 1988; Beckers et al., 1992). The peripheral processes of unipolar cells have been assumed to have axonal characteristics, based on their morphology and the absence of MAP2, a high-molecular-weight protein associated with microtubules in dendrites (Hernández et al., 1989; Riederer and Barakat-Walter, 1992). However, there have been no studies to determine whether the thick peripheral process of a primary sensory neuron maintains the plus end-distal orientation of microtubules characteristic of axons or develops a mixed microtubule population characteristic of dendrites (Bass et al., 1988). Knowledge of the polarity of the microtubules in these neuronal processes is a prerequisite for the prediction of translocator molecules that may function in the bidirectional transport of $\mathrm{HSV}$.

The aims of our study were twofold: to determine the polarity and uniformity of microtubules in the peripheral processes of trigeminal ganglion cells that innervate the cornea, and to determine whether treatment of these processes with microtubuledisrupting drugs at doses that do not inhibit metabolic activity affects the retrograde transport of HSV.

We demonstrate that the microtubules in the peripheral processes of the rabbit trigeminal ganglion cells are uniformly oriented with the minus ends nearer the nucleus and the plus ends directed toward the axon terminal and that microtubule-depolymerizing drugs selectively inhibit the transport of HSV from the cornea to the trigeminal ganglion. Our results provide novel quantitative support for the conclusion that retrograde transport of $\mathrm{HSV}$ in trigeminal neurons is mediated by uniformly polarized microtubules. Furthermore, the results implicate a retrograde translocator molecule, for example, dynein, in the transport of HSV from periphery to cell body.

\section{Materials and Methods}

Microtubule polarity assay. Two 6-month-old rabbits were killed with an overdose of pentobarbital administered intravenously. The eyes were dissected and a silk ligature was placed around the long ciliary nerves, near the origin from the nasociliary branch of the ophthalmic nerve. The nerves were severcd proximal to the ligature and at the point where they pierce the sclera. They were immersed for $30 \mathrm{~min}$ at $0^{\circ} \mathrm{C}$ in piperazine $N, N^{\prime}$-bis (2-ethane sulfonate) (PIPES)-GTP microtubule polymerization buffer containing dimethyl sulfoxide (DMSO), Triton X-100, deoxycholate, and sodium dodecyl sulfate (Heidemann, 1991). After $10 \mathrm{~min}$ in fresh buffer at $22^{\circ} \mathrm{C}$, the nerves were transferred to fresh buffer containing $2 \mathrm{mg} / \mathrm{ml}$ phosphocellulose-purified bovine brain tubulin (kindly provided by M. Kirschner, UCSF, and concentrated by warm/cold cycling prior to use) (Murphy, 1982) and incubated for 20 min at $37^{\circ} \mathrm{C}$. Subsequently, the nerves were fixed in $2 \%$ glutaraldehyde in $100 \mathrm{~mm}$ PIPES, pH 6.9, with $2 \mathrm{~mm} \mathrm{MgCl}_{2}$ and $\mathrm{I} \mathrm{mM} \mathrm{EGTA,} \mathrm{postfixed}$ in $1 \% \mathrm{OsO}_{4}$, dehydrated in graded ethanols, and embedded in EponAraldite.

Care was taken to maintain the orientation of the tissue sections and photographic negatives. Embedded nerves were sectioned perpendicular to the long axis of the nerve from the distal end toward the ligature, and sections were collected on parlodian-coated grids. After counterstaining with uranyl acetate and lead citrate, grids were observed in a Zeiss EM $10 \mathrm{C}$ microscope. Individual axons were photographed at a magnification of $25,000 \times$ and negatives were printed at a final magnification of $45,000 \times$. Overview photographs of the entire nerve were taken at $1250 \times$ and printed at $3000 \times$. Images of microtubules decorated with exogenous tubulin and cut in cross section exhibited hooks corresponding to the sheets of protofilaments polymerized along the length of the microtubule. The handedness of tubulin hooks was scored on electron micrographs. Each axon photographed at high magnification was located in the overview prints of the entire nerve to prevent duplication of microtubule counts

Viral inoculation. A total of $97 \mathrm{BALB} / \mathrm{c}$ mice $4-5$ weeks old were used in the experiments. The mice were anesthetized with an intraperitoneal injection of Avertin (Lumb, 1963). Fifty microliters of a 1:1 solution of $1 \%$ atropine sulfate, $0.5 \%$ proparacaine hydrochloride were applied to each cornea for $15 \mathrm{sec}$. Corneas were scratched from limbus to limbus in a grid pattern consisting of 10 horizontal and 10 vertical scratches made with a 25 gauge needle. Subsequently $10^{7}$ plaque-forming units (pfu) of F strain HSV type 1 in $10 \mu$ l of minimal essential medium was applied to each eye. Mice were monitored daily and treated in accordance with the Society for Neuroscience guidelines for the use of animals in neuroscience research.

Immunofluorescence. To monitor the spread of the viral infection and to determine the time required for retrograde transport of the virus, cryostat sections of eyes and ganglia were immunofluorescently stained for HSV antigen. Ten mice were inoculated with HSV - 1 and maintaincd for $24,48,72,96$, or $120 \mathrm{hr}$. Mice were killed with an overdose of ethyl ether vapor and perfused through the left ventricle with $0.9 \% \mathrm{NaCl}$ followed by $4 \%$ paraformaldehyde in 100 mm sodium cacodylate buffer, $\mathrm{pH}$ 7.4. The trigeminal ganglia, nerves, and eyes were removed as one piece and immediately frozen in liquid Freon cooled by liquid nitrogen. In selected animals the corneas were removed, flattened, and frozen as whole-mounts.

Eyes and trigeminal ganglia were sectioned at $10 \mu \mathrm{m}$ in a cryostat. Serial sections were collected on Vectabond-treated glass slides (Vector, Palo Alto, CA), air dried for $30 \mathrm{~min}$, and rinsed in $100 \mathrm{~mm}$ phosphatebuffered saline, pH 7.2 (PBS). Sections were immunolabeled with a polyclonal rabbit anti-human HSV antibody conjugated to fluorescein (Accurate Chemicals, Westbury, NY), coverslipped in 9:1 glycerol in PBS with 3\%n-propyl gallate, and viewed with a microscope cquipped with epifluorescence optics. Nonspecific staining was prevented by incubating sections with $10 \%$ normal goat serum prior to and during the application of the primary antibody. As a control, we found no immunostaining when the primary antibody to HSV was omitted.

Cytoskeletal-inhibiting drugs. A total of 72 mice were used in the drug experiments; 15 colchicine, $9 \beta$-lumicolchicine, 11 vinblastine, 13 nocodazole, 4 cytochalasin, and 20 controls. Additional mice were used in pilot studies to determine drug dosages and to definc toxicity levels. Twenty microliters of the drug (Sigma Chemical, St. Louis, MO) were injected into the right retrobulbar space of mice using a $50 \mu$ l Hamilton syringe fitted with a 30 gauge needle. The left orbit was injected with the drug vehicle only. The doses of the drugs were as follows: colchicine, 20 or $40 \mu \mathrm{g}$ in $0.9 \% \mathrm{NaCl}$; lumicolchicine, 20 or $40 \mu \mathrm{g}$ in $50 \%$ ethanol: vinblastine, 2.5 or $5 \mu \mathrm{g}$ in $0.9 \% \mathrm{NaCl}$; nocodazole, 2.5 or $5 \mu \mathrm{g}$ in $25 \%$ DMSO; cytochalasin D, $0.4 \mu \mathrm{g}$ in $2 \%$ DMSO. In additional control animals, both orbits were injected with the drug vehicle alone.

I wenty-four hours after the retrobulbar injection of the drug, the mice were reanesthetized and corneas were inoculated with $10^{7}$ pfu of F strain HSV-1. Seventy-two hours after viral inoculation, the mice were weighed to detect systemic illness and killed with an overdose of ethyl ether vapor. The mice were perfused through the left ventricle with $0.9 \% \mathrm{NaCl}$, and the trigeminal ganglia were homogenized in minimal essential medium. Serial dilutions of the homogenate were plated in duplicate over cultures of Vero cells (green monkey kidney cells). incubated for $2 \mathrm{hr}$ at $37^{\circ} \mathrm{C}$ to allow viral adsorption, washed. and overlaid with medium containing $1 \%$ fetal bovine serum and $0.1 \%$ human $\gamma$-globulin. After $72 \mathrm{hr}$, viral plaques were stained and the amount of virus in each trigeminal ganglion was calculated, as previously described (Carter et al., 1992).

In pilot studies, we found less variability in the number of plaqueforming units recovered from the right ganglion following right corneal inoculation than from the left ganglia following left corneal inoculation, perhaps due to variability in the consistency of left corneal scarring. For this reason, for each drug-treated animal, the number of plaqueforming units of virus recovered from the right trigeminal ganglion was expressed as a percentage of those recovered from the right trigeminal ganglion in the vehicle-only control animals. Single-factor analysis of variance with unequal cell sizes was conducted to test for differences in plaque-forming unit distribution. Differences between means were evaluated in post hoc analyses using the Fisher least significant difference test (Winer, 1971).

Autoradiography. To evaluate the effects of the microtubule-depolymerizing drugs on protein synthesis and viral replication, eight addi- 
Figure 1. Electron micrograph of an axon from a rabbit long ciliary nerve treated to demonstrate microtubule polarity. Monomeric tubulin formed protofilament sheets on the walls of endogenous microtubules. When cut in cross section the protofilament hooks are seen to be uniformly oriented. Viewed from the vantage point of the axon terminal in the cornea, the protofilament hooks are directed clockwise (arrows), indicating that the microtubules are oriented with their plus ends toward the axon terminal and their minus ends nearer the cell body in the trigeminal ganglion. Scale bar, $200 \mathrm{~nm}$.

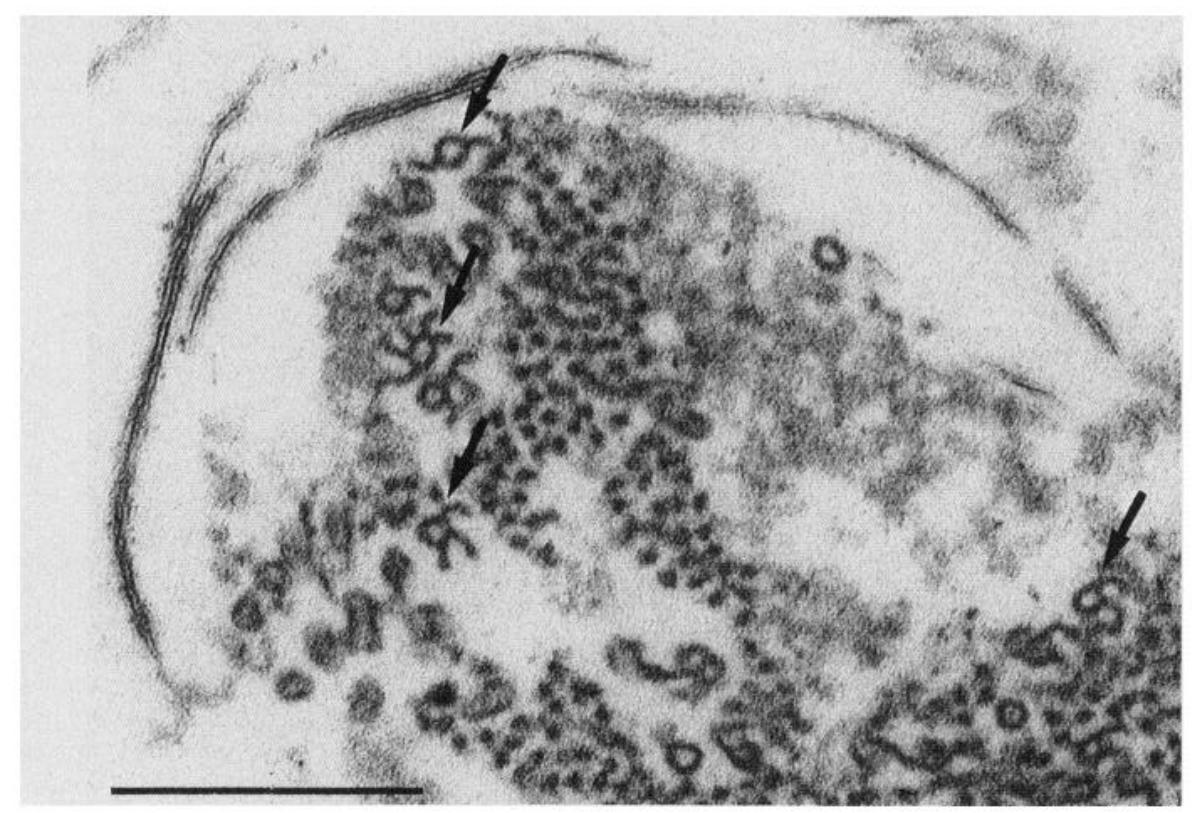

tional mice received retrobulbar $20 \mu \mathrm{l}$ injections of $30 \mu \mathrm{g}$ colchicine, 5 $\mu \mathrm{g}$ vinblastine, $5 \mu \mathrm{g}$ nocodazole, or $0.9 \% \mathrm{NaCl}$, as previously described. After a survival period of $4 \mathrm{~d}$, the mice were injected intraperitoneally with $20 \mu \mathrm{Ci} / g m$ body weight ${ }^{3} \mathrm{H}$-leucine $(82 \mathrm{Ci} / \mathrm{mmol}$; Amersham, Arlington Heights, IL). Six hours later, the mice were killed with an overdose of ethyl ether vapor and perfused through the heart with $3 \%$ glutaraldehyde in $100 \mathrm{~mm}$ sodium cacodylate buffer ( $\mathrm{pH}$ 7.4). Trigeminal ganglia were removed, embedded in glycol methacrylate, and sectioned at $5 \mu \mathrm{m}$, and every fourth section was collected on glass slides. Slides were coated with emulsion, exposed for 3 weeks, developed in Dektol, and stained with toluidine blue as previously described (Margolis et al., 1987).

For each condition, 30 profiles of neurons cut through the plane of the nuclei were chosen from the ophthalmic division of the right ganglion, and the outline of each soma was traced using a $100 \times$ oil immersion lens and a drawing tube. The number of silver grains over each cell soma and the background grains over an adjacent region $0.037 \mathrm{~mm}^{2}$ in area were determined. The area of each cell profile was measured using a digitizing tablet. The data for each neuron were expressed as the corrected number of silver grains per neuron [(grains $/ \mu \mathrm{m}^{2}-$ background $\left./ \mu \mathrm{m}^{2}\right) \times$ cell area in $\left.\mu \mathrm{m}^{2}\right]$. The significance of differences between treatment groups was assessed using analysis of variance.

\section{Results}

\section{Microtubule polarity}

Incubation of rabbit long ciliary nerves under microtubule-polymerizing conditions in the presence of exogenous tubulin resulted in the addition of tubulin in curved protofilament sheets along the long axis of axonal microtubules. The expanded profiles of these microtubules were seen in axons that had been sectioned oblique to the long axis of the nerve. However, when

\section{Table 1. Polar orientation of axonal microtubules}

\begin{tabular}{lllcl} 
& & \multicolumn{3}{l}{ Orientation of hooks } \\
\cline { 3 - 5 } & No. of axons & CW & CCW & $\% \mathrm{CW}$ \\
\hline Myelinated & 20 & 138 & 1 & 99.3 \\
Unmyelinated & 66 & 486 & 54 & 90.0 \\
Total & 86 & 624 & 55 & 91.9
\end{tabular}

a As seen from the periphery looking toward the nucleus. $\mathrm{CW}$, clockwise; $\mathrm{CCW}$, counterclockwise. cross sections of axons were observed, the tubulin protofilaments appeared as hooks extending from individual microtubules (Fig. 1). Since the orientation of the nerves, sections, and photographic negatives was maintained from embedding through printing, and all observations were made from the vantage point of the distal cut end looking toward the cell body, microtubules with clockwise-directed hooks had their plus ends directed toward the observer. In contrast, counterclockwise-directed hooks had their minus ends facing the observer.

Microtubules with distinct hooks were observed in 86 axons (Fig. 1). Remnants of a myelin sheath were observed in 20 (23\%) of the axons and the remaining $66(77 \%)$ axons were unmyelinated. Ninety-one percent of the decorated microtubules had hooks that were directed clockwise, indicating that the fastgrowing end of the microtubules was located nearer the axon terminal in the cornea (Table 1).

\section{Immunofluorescence}

Each scratch with the needle disrupted the stratified corneal epithelium to the extent that epithelial cells were separated by about $50 \mu \mathrm{m}$. The continuity of the underlying corneal stroma was maintained, although the attachment of the epithelium to the stroma occasionally was disrupted. HSV antigen was not uniformly dispersed throughout the cornea. Twenty-four hours after inoculation, there was intense immunohistochemical staining for HSV in nuclei and on plasma membranes of epithelial cells adjacent to the scratch and less intense fluorescence in the cytoplasm. An additional thin line of staining was present along the most superficial layer of corneal stroma in areas where the epithelium had separated from the stroma (Fig. 2). No staining was observed in other regions of the eye or within either trigeminal ganglion at this early time point.

By $48 \mathrm{hr}$, HSV antigens were more widespread in the corneal epithelium. Staining was observed in stromal cells and in some axons in the stroma. Within the trigeminal ganglion about 50 neurons in the ophthalmic division were stained with the antibody. At $72 \mathrm{hr}$, there was conspicuously more staining of the corneal stroma and in the ophthalmic nerves between the eye and the trigeminal ganglion (Fig. $3 A, B$ ). By this time, the number 


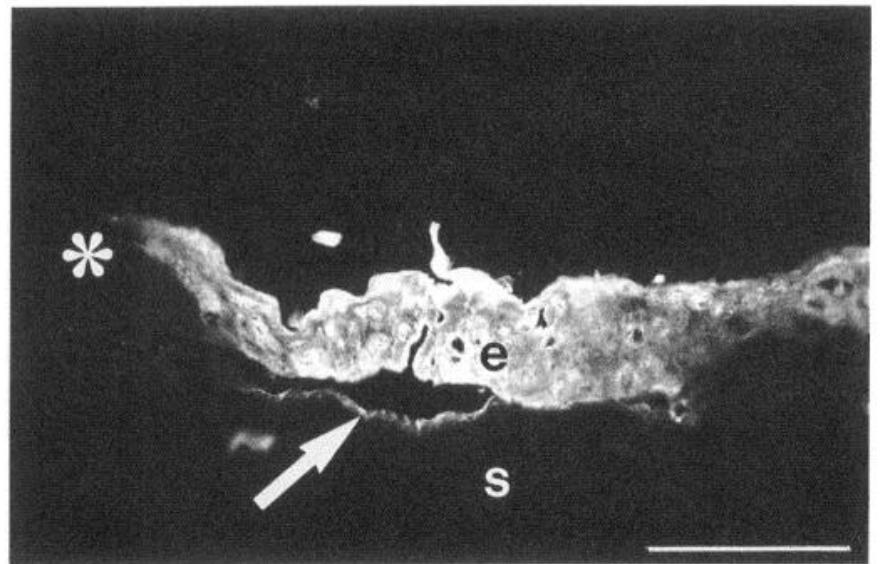

Figure 2. Immunofluorescent staining of HSV antigen in the cornea One day after HSV inoculation, the corneal epithelium $(e)$ and Bowman's membrane at a scratch site (arrow) are stained with HSV antibodies. Viral antigen is not detectable in epithelial cells distant from the scratch site (asterisk) or in the corneal stroma $(s)$ at this time. Scale bar, $100 \mu \mathrm{m}$.

of neurons that were stained with the anti-HSV antibody within the trigeminal ganglion had increased to approximately 250 cells. These neurons were located in the rostral half of the ganglion close to the dorsomedial surface. Staining was present in axons and surrounding Schwann cells, as well as in satellite cells around infected neurons within the ophthalmic division of the ganglion (Fig. $3 C$ ). Four and five days postinoculation, the corneal epithelium and stroma were still stained by the anti-HSV antibody. By $5 \mathrm{~d}$, staining was observed in most of the neurons and surrounding glial cells in the ophthalmic division of the ganglion and within axons coursing both centrally and peripherally (Fig. $3 D$ ). There was no staining of ganglion cells in the contralateral ganglion.

\section{Cytoskeletal-inhibiting drugs}

Although we found that 5 of 11 mice given a retrobulbar injection of $40 \mu \mathrm{g}$ colchicine $24 \mathrm{hr}$ prior to HSV inoculation harbored no infectious virus in the trigeminal ganglia at $3 \mathrm{~d}$ postinoculation, these mice were less active than control mice and lost an average of $7.5 \%$ of their body weight over the $96 \mathrm{hr}$ postinjection period, indicating a systemic effect of the drug. In contrast, mice injected with $20 \mu \mathrm{g}$ colchicine or with lumicolchicine, vinblastine, nocodazole, cytochalasin, or drug vehicle alone suffered neither weight loss nor signs of systemic illness after corneal inoculation with HSV. The animals were active and continued to eat and drink during the $72 \mathrm{hr}$ survival period. Although the eyelids of $30 \%$ of these animals were closed and contained a conjunctival discharge, this change did not relate to an increased amount of virus recovered from the ganglion. In all of

Figure 3. $A$ and $B$, Three days after corneal inoculation, staining for HSV antigen appears in axons in the ophthalmic nerve as it enters the trigeminal ganglion (arrows). Cells in the Harderian gland $\left(^{*}\right)$ and fat cells $(+)$ are autofluorescent. $C$, HSV antigens are present in neurons and surrounding glial cells within the ophthalmic division of the ganglion at $3 \mathrm{~d}$ postinoculation. $D$. Five days after HSV inoculation of the cornea, virions are transported in both central and peripheral processes of ophthalmic ganglion cells. Immunofluorescent staining of HSV antigens can be seen in ophthalmic axons peripheral to the trigeminal ganglion. Scale bars, $100 \mu \mathrm{m}$.
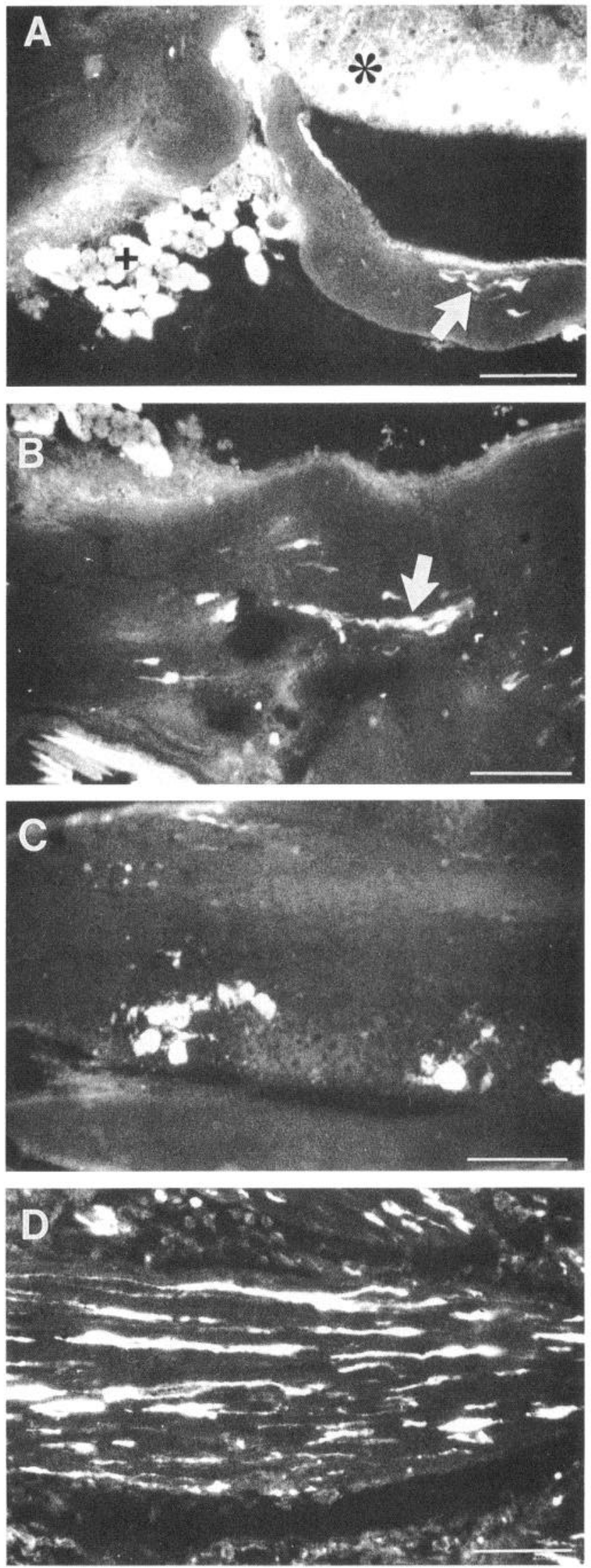


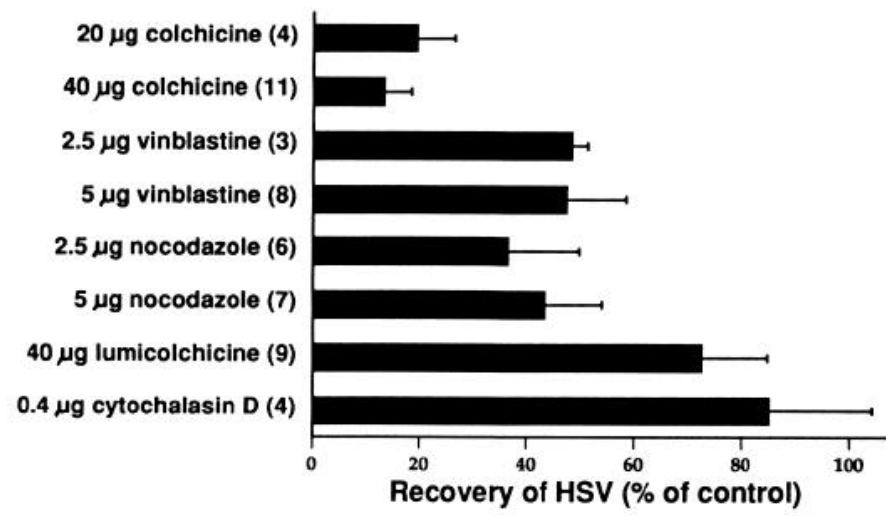

Figure 4. Retrobulbar injection of microtubule-inhibiting drugs significantly reduced the amount of HSV recovered from the trigeminal ganglion. Values for lumicolchicine- or cytochalasin D-treated mice were not significantly different from control values. Bars show means $\pm \mathrm{SD}$. The number of mice for each treatment is shown in parentheses.

the inoculated eyes, the surface of the infected cornea was irregular and there were sites of opacity. Furthermore, the conjunctiva usually appeared inflamed.

There was significantly less infectious HSV recovered from the trigeminal ganglia of mice that received a retrobulbar injection of colchicine, vinblastine, or nocodazole than from ganglia of control mice injected with the drug vehicle alone (Fig. 4). The amount of virus recovered ranged from $13 \%$ to $48 \%$ of the control value, depending on the drug and dosage used. In contrast, when animals were treated with lumicolchicine, the amount of HSV recovered was $73 \%$ of that recovered from control animals. The amount of HSV recovered from the ganglia of mice injected with cytochalasin D was $85 \%$ of the control amount. The variability in the amount of HSV recovered from groups of control mice compared favorably to that observed in our previous dose-response study (Carter et al., 1992).

ANOVA indicated that there was a significant difference in the recovery of virus between drug-treated animals $(p=0.001)$. Multiple comparison tests revealed that the ganglia collected from animals treated with either dose of colchicine or nocodazole or with the higher dose of vinblastine contained significantly less infectious virus than the animals treated with either lumicolchicine or cytochalasin.

\section{Autoradiography}

To determine whether the reduction in the amount of HSV recovered from the trigeminal ganglion was due to a drug-induced decrease in cellular metabolic activity, rather than an effect specific to microtubule polymerization, we evaluated pro-

\section{Table 2. Autoradiographic analysis of protein synthesis}

\begin{tabular}{lcl} 
& Mean & SEM \\
\hline Control & 74.28 & 4.36 \\
Nocodazole & 61.00 & 5.17 \\
Colchicine & $97.52^{*}$ & 8.73 \\
Vinblastine & $108.28^{* *}$ & 6.91
\end{tabular}

Data are provided as the corrected mean number of silver grains per neuron and the SEM.

* Significant at 0.05 .

** Significant at 0.01 .
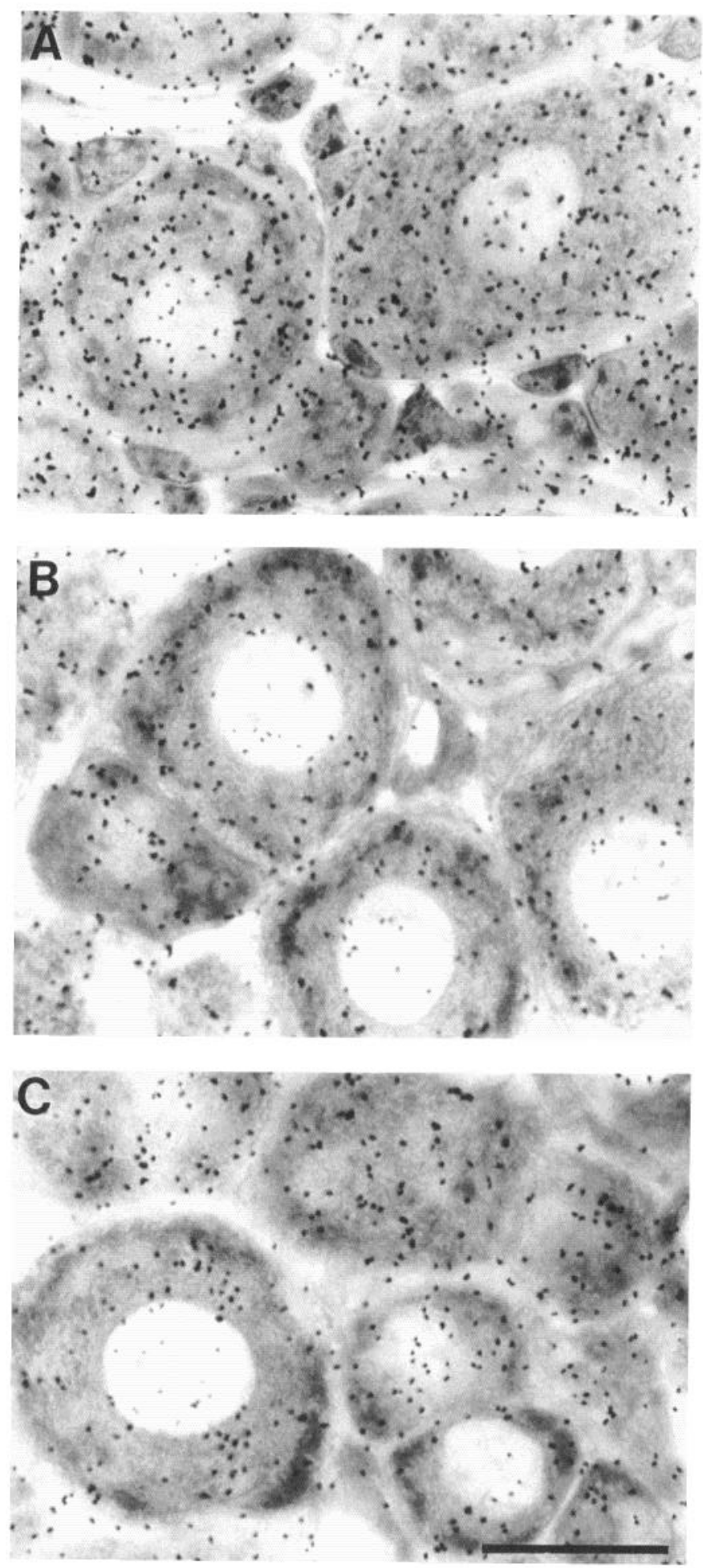

Figure 5. Autoradiograms of neurons in the ophthalmic division of the trigeminal ganglion of mice that received injections of ${ }^{3} \mathrm{H}$-leucine. The mice received a retrobulbar injection of $30 \mu \mathrm{g}$ colchicine $(A), 5 \mu \mathrm{g}$ nocodazole $(B)$, or $0.9 \% \mathrm{NaCl}(C) 4 \mathrm{~d}$ prior to the radioactive amino acid. Significantly more silver grains are present over the cell somata of neurons treated with colchicine. In contrast, the labeling over nocodazole-exposed neurons resembles that of the control. Scale bar, 20 $\mu \mathrm{m}$. 
tein synthesis in ophthalmic neurons following retrobulbar injections of microtubule-inhibiting drugs. As expected, the number of autoradiographic silver grains over ophthalmic neurons increased as the cell profile areas increased $(r=0.649)$. There was a significant difference in the number of silver grains over ganglion neurons in mice treated with microtubule-disrupting drugs when compared to controls ( $p<0.001$ ) (Table 2). More labeling was observed over neurons from mice treated with 30 $\mu \mathrm{g}$ colchicine $(p<0.05)$ or $5 \mu \mathrm{g}$ vinblastine $(p<0.01)$ (Fig. 5). There was no significant difference in labeling over neurons from animals treated with $5 \mu \mathrm{g}$ nocodazole when compared with controls. This may reflect the reversibility of nocodazole binding and the resumption of anterograde transport on newly polymerized microtubules during the $96 \mathrm{hr}$ postinjection period.

\section{Discussion}

HSV is transported bidirectionally in axons, and although microtubules have been implicated, little is known about the microtubule polarity or the motor molecules involved in viral translocation. Several previous studies have suggested a role for microtubules in the bidirectional transport of HSV in sensory neurons in vivo (Kristensson ct al., 1971; Openshaw ct al., 1978; Bosem et al., 1990). Anterograde transport of HSV in the optic nerve is inhibited by injection of the microtubule-depolymerizing drug colchicine into the vitreous chamber (Bosem et al., 1990). Retrograde transport of HSV is also affected by colchicine; direct application of colchicine to the mouse sciatic nerve prevents dorsal root ganglion infection (Openshaw et al., 1978) and promotes animal survival (Kristensson et al., 1971) after inoculation of the footpad with HSV. Although these results implicate microtubules in viral transport, the present study is novel in that it demonstrates quantitatively that HSV transport can be inhibited by microtubule-depolymerizing drugs in dosages that affect microtubules without reducing neuronal protein synthesis.

We have used several microtubule-inhibiting drugs known to interfere with fast axonal transport to provide quantitative evidence that the retrograde transport of HSV from the cornea to the trigeminal ganglion is dependent on microtubules in vivo. Retrobulbar injection of the microtubule-depolymerizing agents colchicine, vinblastine, or nocodazole significantly reduced the amount of virus recovered from the ganglion. The inactive colchicine analog $\beta$-lumicolchicine was used as a control for the microtubule-depolymerizing drugs and was found to have no effect on the retrograde transport of HSV. Moreover, the fact that cytochalasin D, a drug that prevents actin polymerization, did not inhibit viral transport demonstrates the specificity of the virus for microtubules.

Previous studies in which microtubule-depolymerizing drugs were used to inhibit transport of HSV did not assess the metabolic activity of the drug-exposed neurons (Kristensson et al., 1971; Openshaw et al., 1978; Kristensson et al., 1986; Bosem et al., 1990). Therefore, it is impossible to know whether transport was inhibited due to the loss of microtubules or more severe cell destruction. We used quantitative autoradiography to demonstrate that protein synthesis in ophthalmic division neurons was not reduced after retrobulbar injection of colchicine, vinblastine, or nocodazole. In fact, in ganglia from mice treated with colchicine or vinblastine, we observed an increase in the amount of labeling over neuronal somata.

Although these drugs may have many effects on trigeminal ganglion neurons, such as enhanced protein synthesis or reduced protein turnover, we have assumed that the results are related to impaired transport of protein from the cell body, as has been shown previously (Bunt, 1973; Bunt and Lund, 1974; Orcutt et al., 1988). Nocodazole is known to inhibit anterograde transport (Seiler and Weiss, 1987), but its effects are reversible upon removal of the drug. We obscrved a drop in labeling with ${ }^{3} \mathbf{H}$ leucine by $96 \mathrm{hr}$ in mice treated with nocodazole, suggesting that the anterograde transport of newly synthesized proteins had resumed by this time. Moreover, any effects of these drugs on protein synthesis may have relatively little consequence on the efficiency of viral growth, since normal host cell protein synthesis is not required for viral replication. For example, a characteristic of herpes-infected Vero cells is the multiphase shutoff of host macromolecular metabolism following viral penetration (Kwong and Frenkel, 1989). In sum, we conclude that the microtubule-depolymerizing drugs attenuated retrograde transport of the virus, but did not have a generalized inhibitory effect on cellular metabolism.

HSV is thought to travel retrogradely toward the cell nucleus in the absence of a viral envelope or a cell-derived membrane compartment (Lycke et al., 1984, 1988; Marchand and Schwab, 1986). Although HSV has not yet becn cvaluated in in vitro mobility assays, these data suggest that the virus is transported on axonal microtubules in a manner similar to the translocation of fluorescent microspheres, microinjected beads, paraffin droplets, or glass fragments (Adams and Bray, 1983; Colin et al., 1989). It is of interest to note that direct interactions between microtubules and reovirus hemagglutinin protein (Babiss et al., 1979), simian virus large T antigen (Maxwell et al., 1991), and adenovirus capsid protein (Dales and Chardonne1, 1973; Luftig and Weihing, 1975) have been demonstrated in vitro. This suggests that microtubule-dependent translocation may be a common mechanism for viral centripetal transport in infection.

The search for the motor molecules involved in retrograde transport of HSV must begin with the determination of microtubule polarity in the neuronal processes under study, since the known mechanochemical enzymes are direction specific. The method for determining microtubule polarity developed by Heidemann and McIntosh (Heidemann and McIntosh, 1980), in which exogenous monomeric tubulin polymerizes as protofilament appendages on endogenous microtubules, has been used by several investigators to determine the polarity of microtubules in a variety of epithelial cell types. Hooks formed from tubulin subunits indicate that the minus ends of microtubules are oriented toward the apical cell surface of polarized canine kidney cells (Bacallao et al., 1989), teleost retinal pigment epithelial cells (Troutt and Burnside, 1988b), and rat testis Sertoli cells (Redenbach and Vogl, 1991).

The microtubule hooks have also been used to demonstrate microtubule polarity in several types of neurons, including mammalian hippocampal (Baas et al., 1988) and sympathetic neurons (Heidemann et al., 1981; Baas et al., 1991), amphibian olfactory interneurons (Burton, 1988), and amphibian (Burton, 1985) and fish (Troutt and Burnside, 1988a) bipolar sensory neurons. From these studies, it appears that axonal microtubules are uniformly oriented with their plus ends directed toward the axon ending while dendrites contain roughly equal numbers of plus end-distal and minus end-distal microtubules.

Studies of differentiating multipolar neurons in vitro have demonstrated that all neurites initially contain microtubules uniformly oriented with their plus ends directed toward the growth cone (Baas et al., 1989). The microtubules are translo- 
cated from the cell body to the developing neurite in a polarized fashion and possibly under the direction of cytoplasmic dynein (Baas and Ahmad, 1993). As development continues, the single thin axonal process maintains this microtubule organization (Heidemann et al., 1981, 1984; Baas et al., 1988, 1991). However, the thicker dendritic processes acquire microtubules of mixed polarity (Baas et al., 1989).

In contrast to multipolar neurons, dorsal root or trigeminal sensory neurons develop from frankly bipolar cells from which the thicker processes extend toward the periphery, and finer processes project toward the CNS (Stainier and Gilbert, 1991). In the present study, we have demonstrated that the microtubules in the thick peripheral processes of mature trigeminal neurons have their plus ends directed away from the cell body, an orientation that is characteristic of axons. By inference, the two neurites likely acquired and maintained this microtubule orientation during development.

Several enzymes that transduce chemical energy derived from ATP metabolism into mechanical energy capable of moving organelles on microtubule struts have been identified and extensively studied. In mammals, these direction-specific motors include kinesin, which directs movement toward the plus end of microtubules (Vale et al., 1985), and cytoplasmic dynein, which mediates minus end-directed movement (Paschal and Vallee, 1987; Schnapp and Reese, 1989; Vallee et al., 1989). Since we found the orientation of microtubules in peripheral trigeminal axons to be plus end-distal, we hypothesize that the retrograde transport of $\mathrm{HSV}$ from the cornea to the trigeminal ganglion is mediated by a dynein-like ATPase.

Our observation of the dependence of HSV on microtubules for retrograde transport is a significant step in the understanding of how enveloped viruses may use cellular machinery and motors to gain access to the nervous system. Moreover, our finding that the microtubules in trigeminal sensory axons are uniformly polarized suggests that the capsid and tegument may use a dynein-like motor molecule during retrograde transport to the trigeminal ganglion. We further hypothesize that a kinesin-like motor is involved in the anterograde transport of vesicles containing newly synthesized HSV toward both the peripheral tissues and the CNS. Information concerning the motor molecules and their means of interaction with the virus will be directly relevant to the development of novel clinical therapies for herpetic infections and to the use of molecularly engineered herpes vectors for gene therapy.

\section{References}

Adams R, Bray D (1983) Rapid transport of forcign particles microinjected into crab axons. Nature 303:718-720.

Baas PW, Ahmad FJ (1993) The transport properties of axonal microtubules establish their polarity orientation. J Cell Biol 120:14271437.

Baas P, Deitch J, Black M, Banker G (1988) Polarity orientation of microtubules in hippocampal neurons: uniformity in the axon and nonuniformity in the dendrite. Proc Natl Acad Sci USA 85:83358339.

Baas P, Black M, Banker G (1989) Changes in microtubule polarity orientation during the development of hippocampal neurons in culture. J Cell Biol 109:3085-3094.

Baas P, Slaughter T, Brown A, Black M (1991) Microtubule dynamics in axons and dendrites. $J$ Neurosci Res 30:134-153.

Babiss L, Luftig R, Weatherbee J, Wcihing R, Ray U, Ficlds B (1979) Reovirus serotypes 1 and 3 differ in their in vitro association with microtubules. J Virol 30:863-874.

Bacallao R, Antony C, Dotti C, Karsenti E, Stelzer E, Simons K (1989) The subcellular organization of Madin-Darby canine kidney cells during the formation of a polarized epithelium. J Cell Biol 109:28172832.

Beckers HJ, Klooster J, Vrensen GF, Lamers WP (1992) Ultrastructural identification of trigeminal nerve endings in the rat cornea and iris. Invest Ophthalmol Vis Sci 33:1979-1986.

Bisby M (1982) Functions of retrograde axonal transport. Fed Proc 41:2307-2311.

Bosem M, Harris R, Atherton S (1990) Optic nerve involvement in viral spread in herpes simplex virus type 1 retinitis. Invest Ophthalmol Vis Sci 31:1683-1689.

Bunt A (1973) Effects of vinblastine on microtubule structure and axonal transport in ganglion cells of the rabbit retina. Invest Ophthalmol 12:579-590.

Bunt A, Lund R (1974) Vinblastine-induced blockage of orthograde and retrograde axonal transport of protein in retinal ganglion cells. Exp Neurol 45:288-297.

Burton P (1985) Ultrastructure of the olfactory neuron of the bullfrog: the dendrite and its microtubules. J Comp Neurol 242:147-160.

Burton P (1988) Dendrites of mitral cell neurons contain microtubules of opposite polarity. Brain Res 473:107-115.

Carter S, Pereira L, Paz P, LaVail J (1992) A quantitative assay of retrograde transported $\mathrm{HSV}$ in the trigeminal ganglion. Invest Ophthalmol Vis Sci 33:1934-1939.

Colin W, Donoff R, Foote W (1989) Fluorescent latex microspheres as a retrograde tracer in the peripheral nervous system. Brain Res 486:334-339.

Dales S, Chardonnet Y (1973) Early events in the interaction of adenoviruses with HeLa cells. IV. Association with microtubules and the nuclear pore complex during vectorial movement of the inoculum. Virology 56:465-483.

Heidemann S (1991) Microtubule polarity determination based on formation of protofilament hooks. Methods Encymol 196:469-477.

Heidemann S, McIntosh J (1980) Visualization of the structural polarity of microtubules. Nature 286:517-519.

Heidemann S, Landers J, Hamborg M (1981) Polarity orientation of axonal microtubules. J Cell Biol 91:661-665.

Heidemann S. Hamborg M, Thomas S, Song B, Lindley S, Chu D (1984) Spatial organization of axonal microtubules. J Cell Biol 99: 1289-1295.

Hernández. MA, Avila J, Moya F, Alberto C (1989) Rearrangement of microtubule associated protein parallels the morphological transformation of neurons from dorsal root ganglion. Neuroscience 29: 471-477.

Holzer P (1988) Local effector functions of capsaicin-sensitive sensory nerve endings: involvement of tachykinins, calcitonin gene-related peptide and other neuropeptides. Neuroscience 24:739-768.

Kristensson K, Lycke E, Sjöstrand J (1971) Spread of herpes simplex virus in peripheral nerves. Acta Neuropathol (Berl) 17:44-53.

Kristensson K, Lycke E, Roytta M, Svennerholm B, Vahlne A (1986) Neuritic transport of herpes simplex virus in rat sensory neurons in vitro. Effects of substances interacting with microtubular function and axonal flow [nocodazole, taxol and erythro-9-3(2-hydroxynonyl)adenine]. J Gen Virol 67:2023-2028.

Kwong AD, Frenkel N (1989) The herpes simplex virus virion host shutoff function. J Virol 63:4834-4839.

LaVail JH, LaVail MM (1974) The retrograde intraaxonal transport of horseradish peroxidase in the chick visual system: a light and electron microscopic study. J Comp Neurol 157:303-358.

LaVail JH, Meade LB, Dawson CR (1991) Electron microscopic immunocytochemical localization of herpes simplex virus (type 1) in calcitonin gene-related peptide containing trigeminal ganglion neurons. Curr Eye Res [Suppl] 10:23-29.

Luftig K, Weihing $\mathrm{K}$ (1975) Adenovirus binds to rat brain microtubules in vitro. J Virol 16:696-706.

Lumb W (1963) Small animal anesthesia. Philadelphia: Lea and Febiger.

Lycke E, Kristensson K, Svennerholm B, Vahlne A, Ziegler R (1984) Uptake and transport of herpes simplex virus in neurites of rat dorsal root ganglia cells in culture. J Gen Virol 65:55-64.

Lycke E, Hamark B, Johnasson M, Krotochwil A, Lycke J, Svennerholm B (1988) Ilerpes simplex virus infection of the human sensory neuron. An electron microscopy study. Arch Virol 101:87-104.

Marchand CF, Schwab ME (1986) Binding, uptake and retrograde axonal transport of herpes virus suis in sympathetic neurons. Brain Res 383:262-270. 
Margolis TP, Togni B, LaVail JH, Dawson C (1987) CNS localization of HSV-infected neurons after ocular inoculation using systemically administered ${ }^{3} \mathrm{H}$-thymidine. Invest Ophthalmol Vis Sci 28:45.

Maxwell S, Ames S, Sawai E, Decker G, Cook R, Butel J (1991) Simian virus 40 large $T$ antigen and p53 are microtubule-associated proteins in transformed cells. Cell Growth Differ 2:115-127.

Murphy D (1982) Assembly-disassembly purification and characterization of microtubule protein without glycerol. Methods Cell Biol $24: 31-49$

Openshaw H, Stampalia L, Asher L (1978) Retrograde axoplasmic transport of herpes simplex virus. Trans Am Neurol Assoc 103:238239

Orcutt J, Possin D, Bunt-Milam A (1988) Standardized intravitreal injections: evaluation of the effect of anesthesia on rapid axonal transport in the optic nerve. Exp Eye Res 47:621-628.

Paschal B, Vallee R (1987) Retrograde transport by the microtubuleassociated protein MAP 1C. Nature 330:181-183.

Ramon y Cajal S (1952) Histologie du systéme nerveux de l'hommc et des vertébrés, Vol I. Madrid: Instituto Ramon Y Cajal.

Redenbach D, Vogl A (1991) Microtubule polarity in Sertoli cells: a model for microtubule-based spermatid transport. Eur J Cell Biol 54: 277-290.

Riederer BM, Barakat-Walter I (1992) Differential distribution of two microtubule-associated proteins, MAP2 and MAP5, during chick dorsal root ganglion development in situ and in culture. Dev Brain Res 68:111-123.
Roizman B, Sears AE (1991) Herpes simplex viruses and their replication. In: Fundamental virology (Fields B, Knipe D, eds), pp 849895. New York: Raven.

Rozma AJ, Beuerman RW (1982) Density and organization of free nerve endings in the corneal epithelium of the rabbit. Pain 14:105120.

Schnapp B, Reese T (1989) Dynein is the motor for retrograde axonal transport of organelles. Proc Natl Acad Sci USA 86:1548-1552.

Seiler M, Weiss D (1987) Nocodazole irreversibly reduces the capacity of rapid axoplasmic transport in vitro. J Pharmacol Exp Ther 242: 277-283.

Stainier DYR, Gilbert W (1991) Neuronal differentiation and maturation in the mouse trigeminal sensory system, in vivo and in vitro. $\mathrm{J}$ Comp Neurol 311:300-312.

Troutt L, Burnside G (1988a) Microtubule polarity and distribution in teleost photoreceptors. J Neurosci $8: 2371-2380$.

Troutt LL, Burnside B (1988b) The unusual microtubule polarity in teleost retinal pigment epithelial cells. J Cell Biol 107:1461-1464.

Vale R, Reese T, Sheetz M (1985) Identification of a novel forcegenerating protein, kinesin, involved in microtubule-based motility. Cell 42:39-50.

Vallee R, Shpetner H, Paschal B (1989) The role of dynein in retrograde axonal transport. Trends Neurosci 12:66-70.

Winer B (1971) Statistical principles in experimental design. New York: McGraw-Hill. 